\title{
Supermagnetosonic subsolar magnetosheath jets and their effects: from the solar wind to the ionospheric convection
}

\author{
H. Hietala ${ }^{1}$, N. Partamies ${ }^{2}$, T. V. Laitinen ${ }^{2}$, L. B. N. Clausen $^{3}$, G. Facskó ${ }^{2,4}$, A. Vaivads ${ }^{5}$, H. E. J. Koskinen ${ }^{1,2}$, \\ I. Dandouras ${ }^{6,7}$, H. Rème ${ }^{6,7}$, and E. A. Lucek ${ }^{8}$ \\ ${ }^{1}$ Department of Physics, University of Helsinki, P.O. Box 64, 00014 Helsinki, Finland \\ ${ }^{2}$ Finnish Meteorological Institute, P.O. Box 503, 00101 Helsinki, Finland \\ ${ }^{3}$ Bradley Department of Electrical and Computer Engineering, Virginia Tech, Blacksburg, VA 24061-0002, USA \\ ${ }^{4}$ Geodetic and Geophysical Research Institute, Hungarian Academy of Sciences, 9401 Sopron, Pf. 5, Hungary \\ ${ }^{5}$ Swedish Institute of Space Physics, P.O. Box 537, 75121 Uppsala, Sweden \\ ${ }^{6}$ Inst. de Recherche en Astrophysique et Planétologie (IRAP), Univ. of Toulouse, UPS, B.P. 44346, 31028 Toulouse, France \\ ${ }^{7}$ IRAP/CNRS, UMR5187, B.P. 44346, 31028 Toulouse, France \\ ${ }^{8}$ The Blackett Laboratory, Imperial College London, South Kensington Campus, London, SW7 2AZ, UK
}

Correspondence to: H. Hietala (heli.hietala@helsinki.fi)

Received: 25 May 2011 - Revised: 28 October 2011 - Accepted: 18 December 2011 - Published: 5 January 2012

\begin{abstract}
It has recently been proposed that ripples inherent to the bow shock during radial interplanetary magnetic field (IMF) may produce local high speed flows in the magnetosheath. These jets can have a dynamic pressure much larger than the dynamic pressure of the solar wind. On 17 March 2007, several jets of this type were observed by the Cluster spacecraft. We study in detail these jets and their effects on the magnetopause, the magnetosphere, and the ionospheric convection. We find that (1) the jets could have a scale size of up to a few $R_{\mathrm{E}}$ but less than $\sim 6 R_{\mathrm{E}}$ transverse to the $X_{\mathrm{GSE}}$ axis; (2) the jets caused significant local magnetopause perturbations due to their high dynamic pressure; (3) during the period when the jets were observed, irregular pulsations at the geostationary orbit and localised flow enhancements in the ionosphere were detected. We suggest that these inner magnetospheric phenomena were caused by the magnetosheath jets.
\end{abstract}

Keywords. Interplanetary physics (Planetary bow shocks) - Magnetospheric physics (Magnetosheath; Solar windmagnetosphere interactions)

\section{Introduction}

The nature of a shock transition in a collisionless plasma, such as the bow shock of the Earth's magnetosphere in the solar wind, depends strongly on the angle between the upstream magnetic field and the nominal shock normal, $\theta_{\mathrm{Bn}}$
(Stone and Tsurutani, 1985; Burgess et al., 2005). When $\theta_{\mathrm{Bn}}$ is small, i.e., the shock is quasi-parallel, the transition is much more complex than in the quasi-perpendicular case. The reflected particles can stream against the upstream solar wind flow and interact with the incident plasma over long distances. This interaction triggers instabilities and creates multiple types of waves and fluctuations in a region called foreshock. The foreshock is most pronounced for a high Mach number bow shock, and when the upstream magnetic field is aligned with the solar wind velocity, i.e., during radial interplanetary magnetic field (IMF) (Omidi et al., 2009). Some of the foreshock waves can steepen into larger structures, such as Large Amplitude Magnetic Structures (SLAMS), that convect back to the bow shock and modify it (Schwartz, 1991; Lucek et al., 2002, 2008). Satellite observations and simulation studies have led to the picture of quasi-parallel shock being a patchwork of structures that vary in space and time (e.g., Greenstadt et al., 1982; Gosling et al., 1989; Onsager et al., 1990; Schwartz and Burgess, 1991; Omidi et al., 2005, 2009; Blanco-Cano et al., 2006, 2009).

The non-thermal nature of the upstream side of the quasiparallel shock has been recognized since the early satellite missions (Asbridge et al., 1968). The complex structures behind the shock in the magnetosheath, however, have only recently come under active research owing to the observations around the subsolar magnetopause by Cluster (Escoubet et al., 1997) and Time History of Events and Macroscale Interactions during Substorms (THEMIS) (Angelopoulos, 
2008) spacecraft (e.g., Retinò et al., 2007). One of these intriguing phenomena are the "transient flux enhancements" (Nemecek et al., 1998), or "high kinetic energy jets" (Savin et al., 2008), that have been interpreted as not being produced by reconnection. Savin et al. (2008) found more than 140 events of anomalously high kinetic energy density. The jets seem to occur preferentially during radial IMF (Nemecek et al., 1998; Shue et al., 2009; Hietala et al., 2009), or behind a quasi-parallel shock (Amata et al., 2011). When ramming into the magnetopause, the jets can cause large perturbations (Hietala et al., 2009; Amata et al., 2011) and even sunward flows, as the magnetopause recovers from the impact (Shue et al., 2009).

Hietala et al. (2009) proposed, based on Cluster observations on 17 March 2007, a general plasma physics mechanism for the formation of fast, even supermagnetosonic jets behind a rippled high Mach number shock. They pointed out that such local changes in the curvature of a shock front - intrinsic for quasi-parallel shocks - can result in fast bulk flows on the downstream side. Briefly, in the regions where the local shock normal is quasi-perpendicular to the upstream velocity, the shock mainly deflects plasma flow while the speed stays close to the upstream value. Together with the compression of the plasma, these localised streams can lead to jets with a kinetic energy density that is several times higher than the kinetic energy density in the upstream region.

The aim of the present paper is to study the jets of 17 March 2007, in depth and in the magnetospheric context. We start by describing the mechanism for the jet formation proposed by Hietala et al. (2009), with a new emphasis on the dynamic pressure of the jets, since their high pressure is the key factor in their interaction with the magnetosphere. In Sect. 3, we analyse near-Earth observations from the evening of 17 March 2007, which was characterised by a long period of steady solar wind with radial IMF. We first present an example of a jet in detail, and then analyse the 3-h period of Cluster magnetosheath data containing several jets to study their effects on the magnetopause. In addition, we investigate how these variations, with a scale that is much smaller than the global magnetohydrodynamic (MHD) scale but larger than the kinetic scales (i.e., a "mesoscale" phenomenon), are transmitted from the magnetosheath into the magnetosphere. For that purpose, we use observations from the Geostationary Operational Environmental Satellites (GOES) (Grubb, 1975) as well as Super Dual Auroral Radar Network (SuperDARN) (Greenwald et al., 1995; Chisham et al., 2007) measurements from the same time interval. Discussion and conclusions are given in Sects. 4 and 5.

\section{Mechanism}

Let us first consider the plasma flow across a high $M_{\mathrm{A}}$ (Alfvén Mach number) MHD shock wave. The shock primarily decelerates the component of the upstream veloc- a)

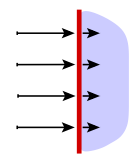

b)

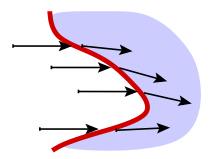

c)

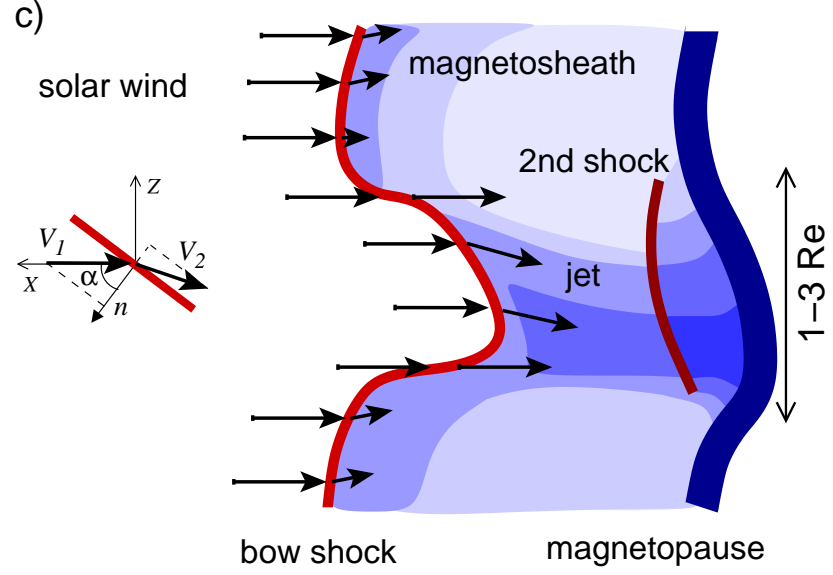

Fig. 1. Top: schematic picture of the velocity field across a high Mach number shock that is either planar (a) or rippled (b). The red line depicts the shock, and the blue area is the downstream side. Bottom: illustration of the effect of a bow shock ripple, adapted from Hietala et al. (2009). The variation of the plasma number density in the downstream region is illustrated by the shading: dark blue indicates density enhancement, light blue indicates density depletion. The jet perturbs the magnetopause which is depicted by the thick blue line. In the particular case where the jet is supermagnetosonic in the frame of the magnetopause, an additional, weak shock forms. The inset details the flow deflection when $\boldsymbol{V}_{1}$ is not parallel to $\boldsymbol{n}$. Note that the picture is not to scale in the horizontal direction.

ity $V_{1}$ that is normal to the shock front, i.e., the RankineHugoniot jump conditions give $V_{1 n}=r V_{2 n}$ and $V_{1 t} \approx V_{2 t}$. Here $r$ is the shock compression ratio. If the shock is planar, with an orientation illustrated in Fig. 1a, the density increase and the flow velocity decrease are $\rho_{2}=r \rho_{1}$, and $V_{2}=\frac{1}{r} V_{1}$. The dynamic pressure of the plasma flow is thus smaller on the downstream side of the shock than on the upstream side:

$P_{\mathrm{dyn} 2}=\rho_{2} V_{2}^{2}=\frac{1}{r} \rho_{1} V_{1}^{2}=\frac{1}{r} P_{\mathrm{dyn} 1}$.

However, if the shock is locally rippled with a geometry sketched in Fig. 1b, the plasma speed stays close to the upstream value $V_{2} \approx V_{1}$ near the edges of the ripple. Since the plasma is still compressed, $\rho_{2} \approx r \rho_{1}$, the dynamic pressure can in fact be larger on the downstream side than on the upstream side:

$P_{\mathrm{dyn} 2} \approx r \rho_{1} V_{1}^{2}=r P_{\mathrm{dyn} 1}$.

Next, let us apply this idea to the quasi-parallel bow shock between the solar wind and the magnetosphere (Fig. 1c). Crossing the bow shock leads to efficient compression and 
deceleration of the solar wind plasma in the regions where the angle $\alpha$ between $\boldsymbol{V}_{1}$ and $\boldsymbol{n}$ is small. This is the typical situation near the bow shock nose. Still, if the bow shock is locally rippled, there can be small regions where $\alpha$ is large, and the bow shock mainly deflects the solar wind flow. In addition, depending on the ripple geometry, the flow behind the shock can converge causing local density enhancements, or diverge causing density depletions. This structuring of the magnetosheath is illustrated by the blue shading in Fig. 1c. The density variations in the foreshock of a quasi-parallel bow shock contribute to the shock rippling, and some of these density variations can be trasmitted into the magnetosheath as well (Fairfield et al., 1990). Yet the ripple induced structuring takes place even for smooth uptream conditions, once a ripple is formed.

The high speed together with the increased density behind the ripple lead to a jet of very high dynamic pressure, as stated by Eq. (2). The dynamic pressure of the jet perturbs the shape of the magnetopause. Furthermore, there is the possibility that the speed $V_{2}$ of this jet in the magnetosheath is still supermagnetosonic in the reference frame of the magnetopause. In this particular case a second, weak shock front forms closer to the magnetopause.

Hietala et al. (2009) inferred, based on the analysis of the Cluster multi-spacecraft observations, that the lower limit for the scale of the particular bow shock ripple and the jet under consideration was of the order of the spacecraft separation: $\gtrsim 50$ ion inertial lengths, $\sim 8000 \mathrm{~km}, \sim 1.2 R_{\mathrm{E}}$. In the present paper we expand the analysis to cover GOES and SuperDARN observations as well, and argue that the upper limit for the jet scale is of the order of $6 R_{\mathrm{E}}$.

\section{Analysis}

To investigate the effects of supermagnetosonic jets, we use data measured on 17 March 2007, at the near-Earth locations shown in Fig. 2. The Advanced Composition Explorer (ACE) (Stone et al., 1998) and Wind (Acuña et al., 1995) spacecraft, acting as the solar wind monitors, were located near the Lagrangian point $\mathrm{L} 1$ at $(X, Y, Z)_{\mathrm{GSE}}=(237,36.4$, -18.6) $R_{\mathrm{E}}$ and $(198.7,-33,-18.7) R_{\mathrm{E}}$. Geotail (Nishida, 1994) was in the turbulent foreshock region near the subsolar point. The four Cluster spacecraft (C1-C4) were on an outbound orbit close to the nose of the magnetosphere, while the magnetopause moved across them several times. The spacecraft constellation was quite flat in the nominal plane of the magnetopause, since $\mathrm{C} 3$ and $\mathrm{C} 4$ were close to each other $\left(950 \mathrm{~km}, 0.15 R_{\mathrm{E}}\right.$ apart $)$, while the others were slightly more than $7000 \mathrm{~km}\left(>1 R_{\mathrm{E}}\right)$ away. GOES-11 and 12 were in the geostationary orbit on the dayside. In addition, we show ionospheric velocity data measured by the SuperDARN radars in the Northern Hemisphere.
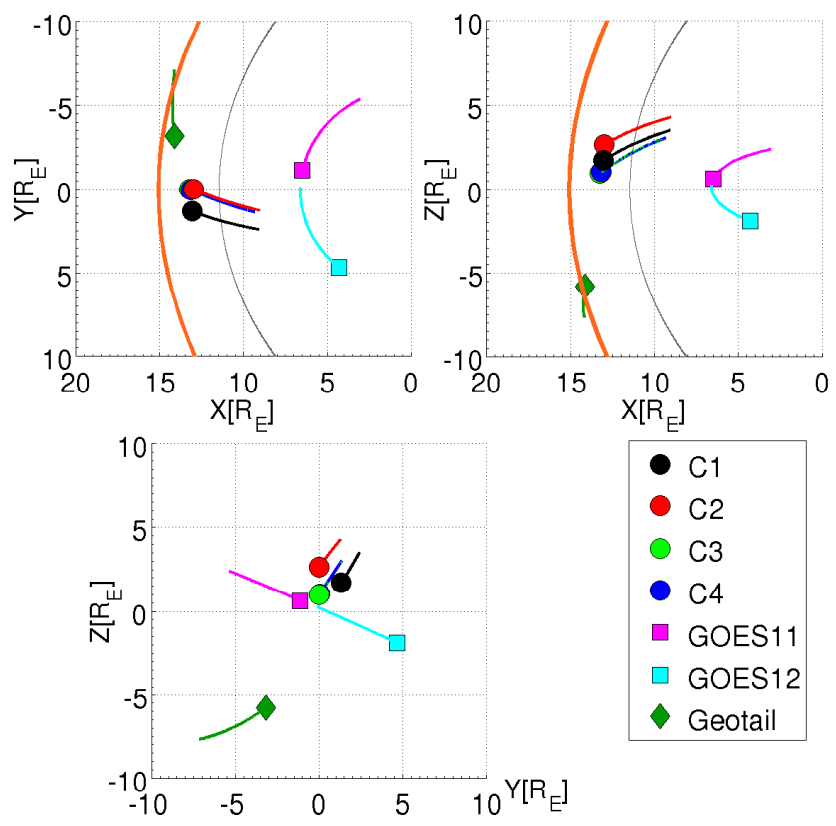

Fig. 2. The orbits of Cluster, GOES, and Geotail spacecraft on 17 March 2007, 17:00-20:30 UT in Geocentric Solar Ecliptic (GSE) coordinates. The markers show the spacecraft locations at the end of the interval. The orange curve depict the model bow shock (Merka et al., 2005) and the grey curve the model magnetopause (Shue et al., 1998) for the observed upstream conditions.

\subsection{Solar wind: ACE, Wind, and Geotail observations}

According to ACE and Wind measurements, the IMF direction was fluctuating during the first half of the day, although its magnitude stayed quite constant at 2.5-3 nT (not shown). The ACE observations for the second half of the day are shown in Fig. 3, time-shifted by $44 \mathrm{~min}$ to account for the solar wind propagation to the magnetopause. In the morning, there had been short intervals of quasi-radial IMF, i.e., of cone angle $<30^{\circ}$. However, shortly after 12:00 UT the average IMF direction became radial and steady for several hours: Fig. $3 \mathrm{~b}$ displays the angle $\theta$ between the IMF direction and the $X_{\mathrm{GSE}}$ axis, both the 16-s resolution measurement and its 10 -min average. The 10 -min average was $150-180^{\circ}$ from 12:20 to 20:20 UT, with a 50-min exception around 16:30 UT and a 20-min exception near 17:30 UT, in addition to three shorter ones.

Late in the evening, the heliospheric current sheet crossed the near-Earth space, $B_{X}$ turned positive, and the overall IMF configuration changed to more Parker spiral like (Fig. 3a). Wind, though closer to the Earth, was the first to observe the current sheet at 19:50 UT, while ACE detected the crossing at 20:09 UT. This can be understood given the estimated current sheet normal direction (obtained using IMF cross product and Minimum Variance Analysis): $\quad \boldsymbol{n}_{\text {Wind }}=(-0.47,0.55,-0.67)_{\mathrm{GSE}}$ and $\boldsymbol{n}_{\mathrm{ACE}}=$ $(-0.30,0.40,-0.87)_{\mathrm{GSE}}$. The arrival of the current sheet 


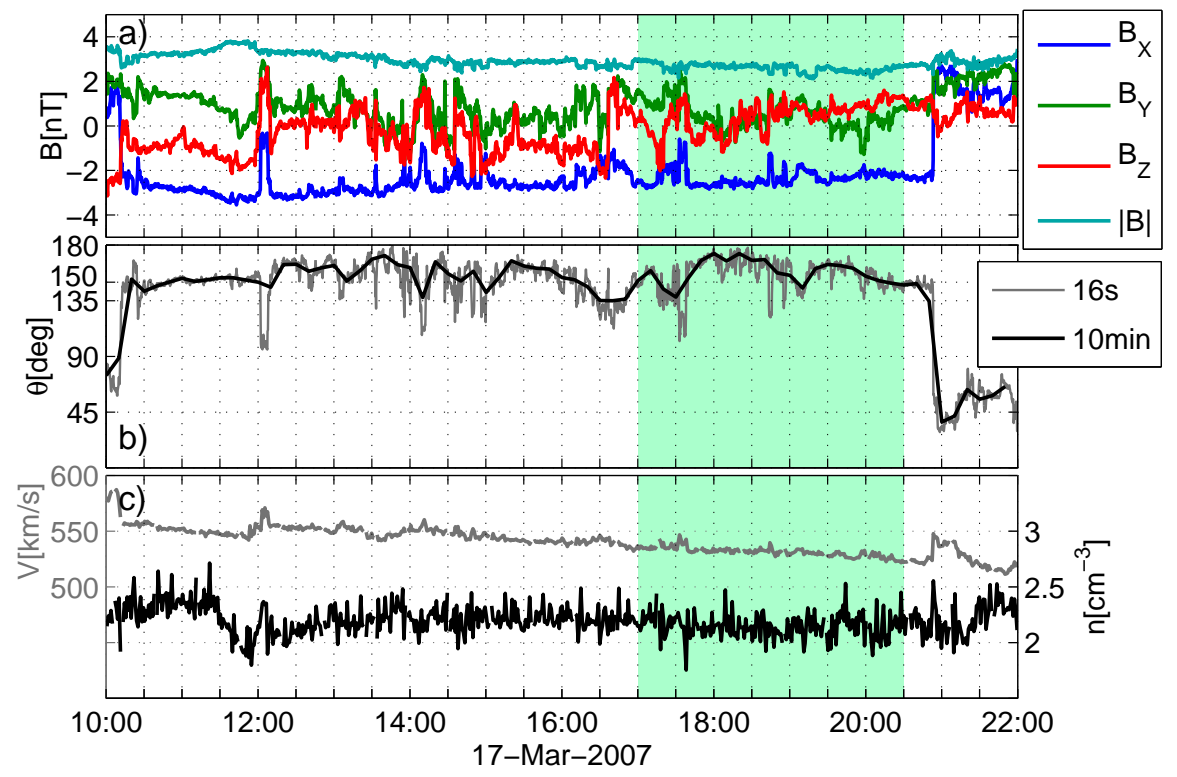

Fig. 3. Upstream solar wind data from ACE, time-shifted by $44 \mathrm{~min}$ to account for the solar wind propagation to the magnetopause. (a) Interplanetary magnetic field in GSE coordinates. (b) The angle $\theta$ between the magnetic field direction vector and the $X_{\mathrm{GSE}}$-axis. (c) Solar wind speed and number density. The time interval corresponding to Cluster magnetosheath jet observations is given in sea-green colour.

at Earth was indicated by a change in the magnetosheath characteristics observed by Cluster as the bow shock nose changed from parallel to more perpendicular. Due to the current sheet orientation, this transition took place at about 20:20 UT, i.e., about $30 \mathrm{~min}$ earlier than propagation from ACE with the solar wind speed would imply (Fig. 3a and b).

The Cluster magnetosheath jet observations took place within the interval from 17:00 to 20:30 UT (sea-green in Fig. 3). During this period, the IMF of $\sim 2.6 \mathrm{nT}$ was radial and steady: the ACE 16-s resolution measurements show only a few short excursions to $\theta<135^{\circ}$. The $B_{\mathrm{Y}}$ and $B_{\mathrm{Z}}$ (Fig. 3a) were small with some fluctuations around zero.

The upstream plasma measurements (Fig. 3c) show that the undisturbed solar wind was quite fast, $\quad V \sim 530$ $540 \mathrm{~km} \mathrm{~s}^{-1}$, and steady. As the plasma number density was $n \sim 2 \mathrm{~cm}^{-3}$, the dynamic pressure was $\sim 1 \mathrm{nPa}$. The Alfvén Mach number of the solar wind flow was $\sim 13$. As the proton temperature measurements differ significantly between the two upstream spacecraft, and the Wind measurements for the electron temperature are not available, the estimate for the solar wind temperature is uncertain. We estimate that the sonic Mach number $M_{\mathrm{S}} \sim 8-9$, and the magnetosonic Mach number $M_{\mathrm{MS}} \sim 7-8$. Accordingly the plasma beta was larger than unity, $\beta \sim 2.5-3.5$.

Closer to the Earth, Geotail was in the turbulent foreshock during the event, and the bow shock moved over the spacecraft several times. The observed shock location matches quite well with the empirical model proposed by Merka et al. (2005) for the measured upstream solar wind parameters. We thus conclude that the bow shock was close to its nominal location during the event, though fluctuating.

\subsection{Magnetosheath: Cluster observations}

\subsubsection{Example of a supermagnetosonic jet}

In this subsection, we concentrate on the detailed stucture of the jet observed by the Cluster quartet between 18:14 and 18:16 UT. The general features of this jet have previously been described in Hietala et al. (2009). The absolute values of the plasma density reported here are somewhat smaller than in the previous paper due to re-calibration of the Cluster Ion Spectroscopy CIS-HIA (Rème et al., 2001) data in February 2010. The conclusions are not altered by this procedure.

Figure 4 shows the magnetic field and plasma density observations from the four satellites. The former are from the Fluxgate Magnetometer (FGM) instrument (Balogh et al., 2001). The latter have been estimated based on a linear fit to the spacecraft potential measurements of the Electric Field and Wave (EFW) experiment (Gustafsson et al., 1997), using CIS-HIA ion and Plasma Electron and Current Experiment (PEACE) (Johnstone et al., 1997) electron density measurements for calibration (H. Laakso and Y. Khotyaintsev, personal communication, 2011). As data from the EFW instrument are available from every spacecraft with high, 0.2-s time resolution, they are well suited to detect fast density variations. In this study, we use them to identify different plasma regions.

At the beginning of the interval, all four spacecraft were inside the magnetosphere, which is indicated by strong magnetic field and low density. First, the magnetopause moved inwards across the quartet at a speed of $\sim 250 \mathrm{~km} \mathrm{~s}^{-1}$ 


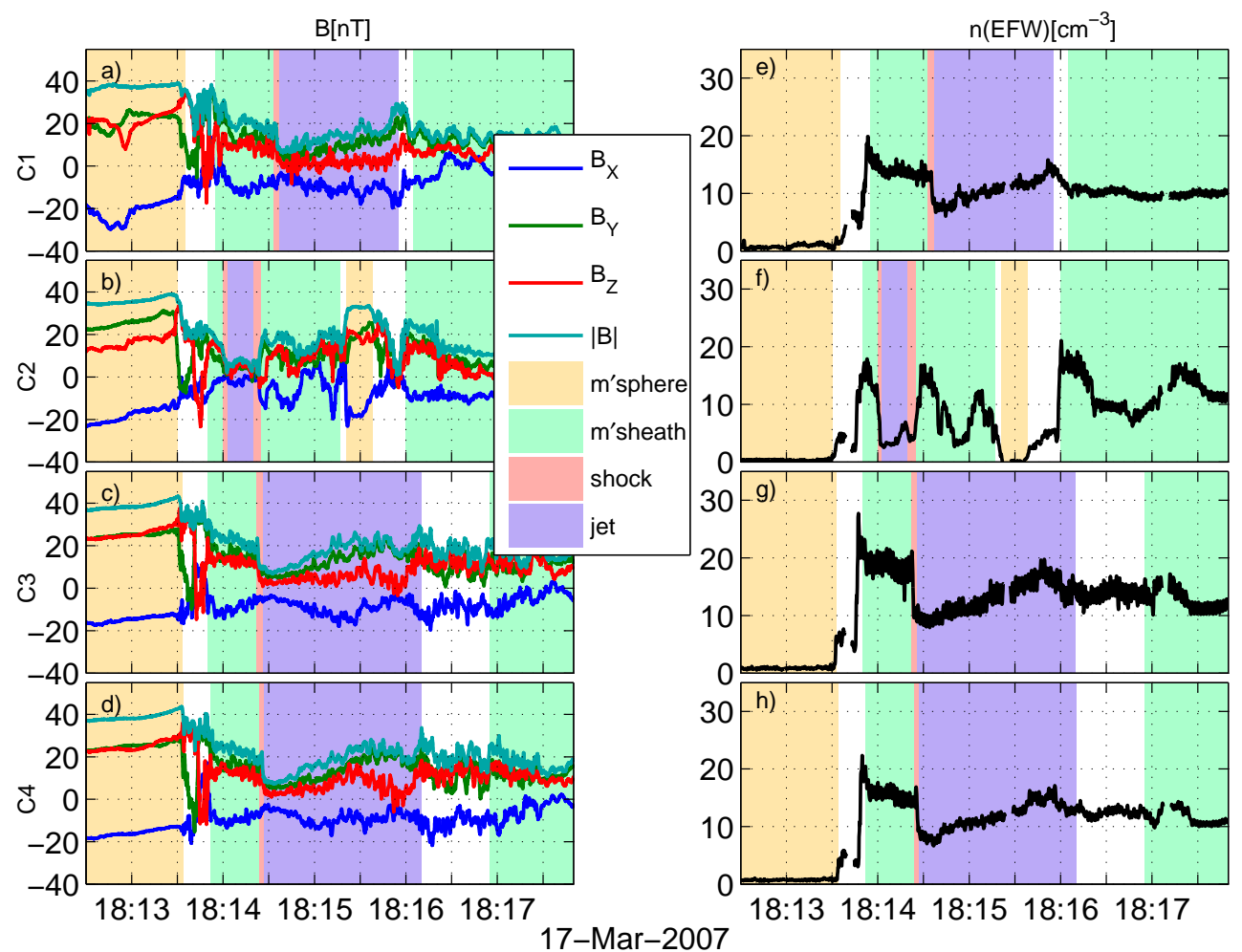

Fig. 4. Cluster observations near a supermagnetosonic magnetosheath jet. Left: magnetic field from all four spacecraft in GSE coordinates. Right: plasma density estimate based on a linear fit to the spacecraft potential measurements of the EFW instrument, using CIS-HIA ion and PEACE electron density measurements for calibration. CIS-HIA data were available only for C1 and C3. The colour panels mark different plasma regions. White background between colour panels represents transition between two regions. Panels (a-d) are from Hietala et al. (2009).

(obtained using four-spacecraft timing). Then, a weak shock passed over the spacecraft moving in the same direction. We will discuss the details of this shock later in this subsection.

After the shock, Cluster entered the supermagnetosonic jet with plasma speed close to $500 \mathrm{~km} \mathrm{~s}^{-1}$ (see also the first panel of Fig. 5). The plasma density (from CIS-HIA measurements) and the magnetic field, while slightly lower than in the typical magnetosheath conditions, were more than a factor of 2 larger than in the pristine solar wind. At the location of $\mathrm{C} 2$ (Fig. $4 \mathrm{~b}$ and $\mathrm{f}$ ), the weak shock and the magnetopause moved back across the spacecraft. $\mathrm{C} 2$ then stayed in the magnetosphere for several seconds around 18:15:30 UT. The other three spacecraft were inside the jet for about $1.5 \mathrm{~min}$. While in the jet, they observed a gradual increase in both magnetic field magnitude and plasma density. After 18:18 UT, the three spacecraft moved into more typical magnetosheath plasma.

We have estimated the properties of the weak shock with several methods using the magnetic field observations and the C1/CIS-HIA ion measurements (e.g., Schwartz, 1998). Minimum Variance Analysis and magnetic co-planarity were used to calculate the shock normal vector from $\mathrm{C} 1$ observations. These estimates could then be combined with the
Mass Flux Algorithm to calculate the shock speed. The 4spacecraft timing method, on the other hand, gives both the normal direction and the shock speed.

The first panel of Fig. 5 displays the results of this analysis. The shock speed was between 130 and $190 \mathrm{~km} \mathrm{~s}^{-1}$. The angle between the shock normal and the local magnetic field direction $\theta_{\mathrm{Bn}}$ was around $40^{\circ}$. The group of lines in black, grey, and white depict the results of the different methods for the component of plasma velocity parallel to the shock normal $V_{\mathrm{n}}$ in the frame of reference moving with the shock. At the crossing of the weak shock $V_{\mathrm{n}}$ indeed exceeded the magnetosonic speed $V_{\mathrm{MS}}$. The fast MHD wave speed $V_{\mathrm{f}}\left(\theta_{\mathrm{Bn}}\right)$ for each shock normal estimate was close to, but less than the magnetosonic speed.

The rest of Fig. 5 shows further information on the ion dynamics during the interval under consideration. In Figs. $5 \mathrm{~b}$ and $5 \mathrm{c}$, the bulk flow direction is displayed in the $\left(-Z_{\mathrm{GSE}}\right.$, $\left.X_{\mathrm{GSE}}\right)$ and $\left(-Y_{\mathrm{GSE}}, X_{\mathrm{GSE}}\right)$ planes. Deflection of the arrows to the left thus means flow deflection to the positive $Z_{\mathrm{GSE}}$ or $Y_{\mathrm{GSE}}$ direction. This direction is expected of the overall magnetosheath flow given the $\mathrm{C} 1$ location. During the jet the flow was, however, deflected to the negative $Z_{\mathrm{GSE}}$ direction. The observed pattern of the supermagnetosonic flow after the 

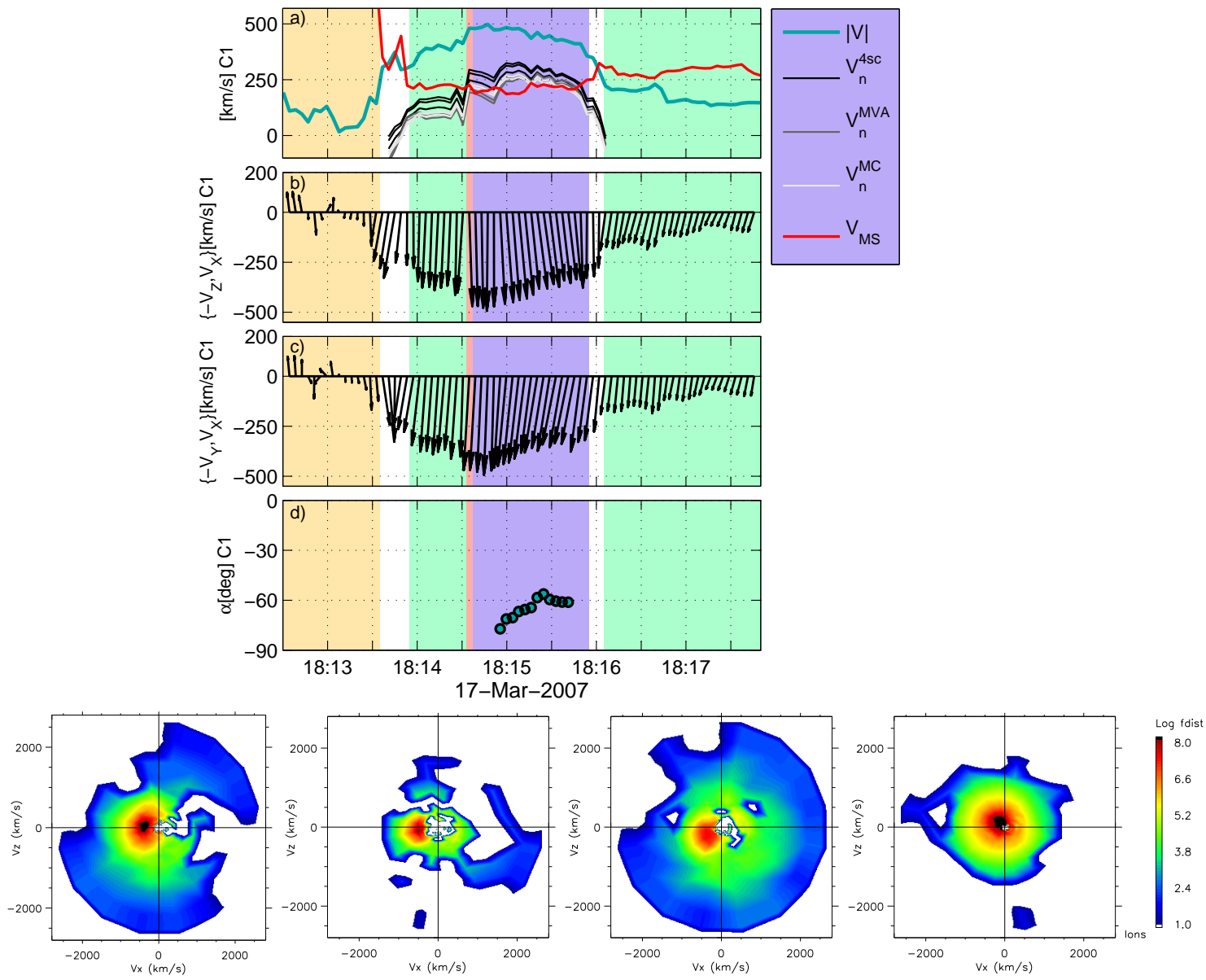

Fig. 5. C1/CIS-HIA velocity observations near a supermagnetosonic magnetosheath jet. The colour coding for different plasma regions is the same as in Fig. 4. (a) The total plasma speed $V$ is depicted by the light blue curve and the magnetosonic speed $V_{\mathrm{MS}}=\sqrt{V_{\mathrm{A}}^{2}+V_{\mathrm{S}}^{2}}$ by the red curve. The group of curves in black, grey, and white depict the component of plasma velocity parallel to the shock normal $V_{\mathrm{n}}$ in the frame of reference moving with the shock. The three black lines show the results of the four-spacecraft timing method, the two grey lines of Minimum Variance Analysis (MVA) and Mass Flux Algorithm, and the two white lines of magnetic co-planarity (MC) and Mass Flux Algorithm. (b, c) Bulk velocity projection to $\left(-Z_{\mathrm{GSE}}, X_{\mathrm{GSE}}\right)$ and $\left(-Y_{\mathrm{GSE}}, X_{\mathrm{GSE}}\right)$ planes. Deflection of the arrows to the left thus means flow deflection to the positive $Z_{\mathrm{GSE}}$ or $Y_{\mathrm{GSE}}$ direction. (d) The angle $\alpha$ (see the inset of Fig. 1c) calculated from the observed velocity deflection using the Rankine-Hugoniot jump conditions for high $M_{\mathrm{A}}$ and compression ratio $r=4$. The calculation is not expected to be valid at the edges of the jet where the shock is weak, and hence $\alpha$ is shown for the center only. Bottom: HIA ion distributions in the ( $\left.V_{\mathrm{X}}, V_{\mathrm{Z}}\right)$ plane (cut through $V_{\mathrm{Y}}=0$ ) at 18:14:06, 18:14:43, 18:15:33, and 18:16:27 UT. The scale is in distribution function units, i.e., phase space density of ions $\cdot \mathrm{s}^{3} \mathrm{~km}^{-6}$. Panels (b) and (d) are from Hietala et al. (2009).

weak shock suggests that there was a ripple in the bow shock similar to the one in Fig. 1c moving in the $\sim Z_{\mathrm{GSE}}$ direction. This interpretation is supported by the observed density and flow speed profiles. The flow pattern in the $Y_{\mathrm{GSE}}$ reveals more of the three-dimensional structure of the ripple, but is not that exceptional.

Figure 5d shows the upstream angle $\alpha$ (defined in the inset of Fig. 1c), for the supermagnetosonic jet. This angle can be calculated from the observations using the RankineHugoniot jump conditions by considering both the downstream and upstream data, and taking $r=4$ corresponding to high $M_{\mathrm{A}}$. During the main velocity deflection, $\alpha$ was surprisingly large, $\sim-65^{\circ}$.
Last, the evolution of the observed ion distribution when the jet passed over Cluster 1 is illustrated in the four contour plots of Fig. 5. The distributions are cuts through $V_{Y}=0$. The two first ones, from 18:14:06 and 18:14:43, are from both sides of the weak shock. The jet had a distinct, solar wind-like core that was cold $\left(T_{i} \sim 1.5-2.5 \mathrm{MK}, T_{e} \sim 0.5-\right.$ $0.6 \mathrm{MK})$, yet warmer than the pristine solar wind. There was also an interesting lack of higher energy ions from the weak shock until about 18:15. The flow deflection to the negative $Z$ direction is particularly visible at 18:15:33 UT, the third distribution from the left. The last distribution, from 18:16:27 UT, depicts the transition to warmer, symmetric quasi-Maxwellian plasma. 

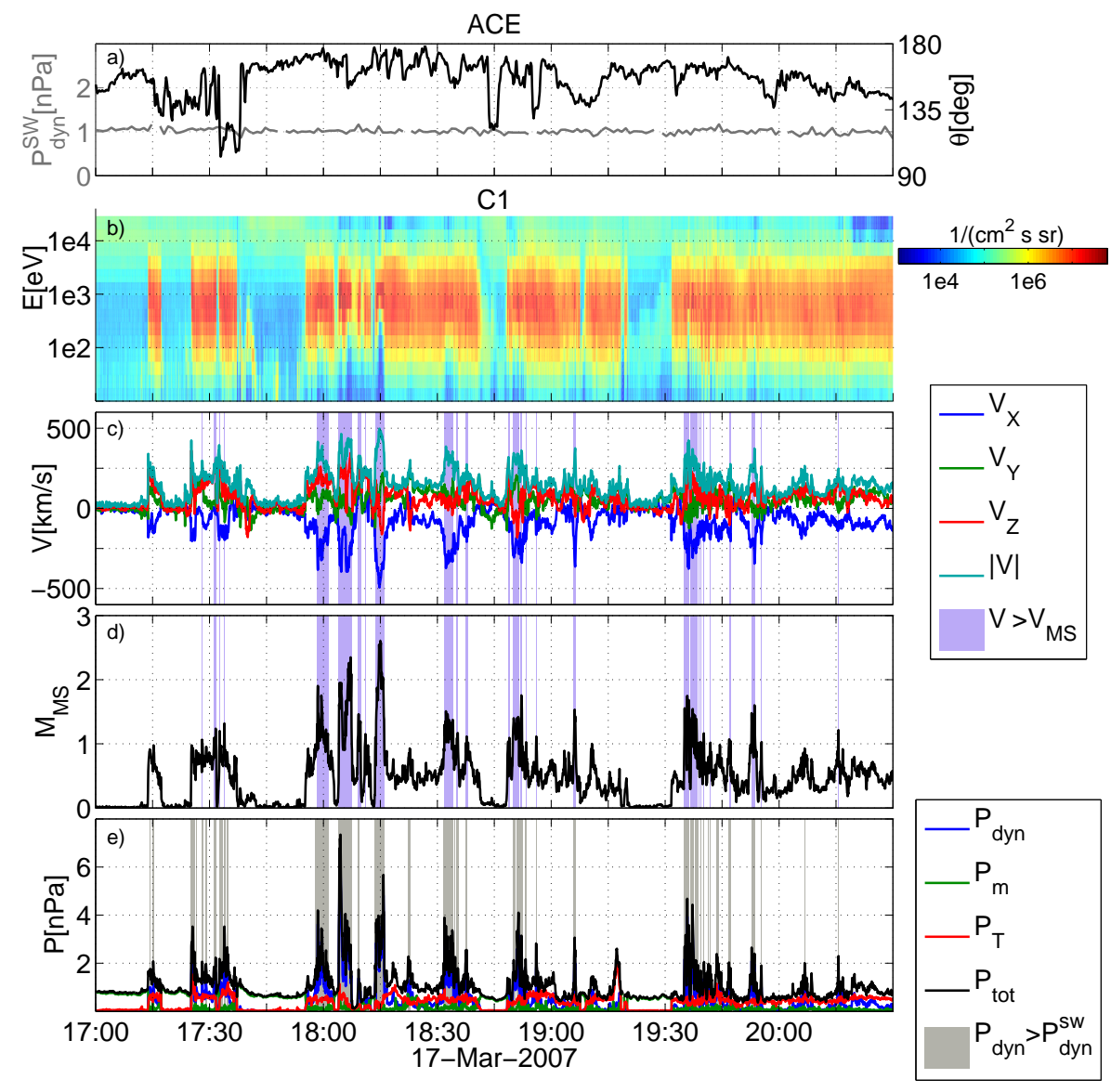

Fig. 6. The uppermost panel: upstream solar wind data from the ACE satellite (time-shifted by 44 min). (a) Dynamic pressure of the solar wind and the angle $\theta$ between the magnetic field direction vector and the $X_{\mathrm{GSE}}$-axis. Lower panels: Cluster C1 observations of jets and pressure pulses in the magnetosheath. (b) Omni-directional ion energy spectrograms. (c) Ion velocity measurements in the GSE coordinates. The intervals when the total plasma speed was larger than the local magnetosonic speed are shaded in blue. (d) Magnetosonic Mach number $V / V_{\mathrm{MS}}$. (e) The dynamic pressure, the magnetic pressure, and the thermal pressure of the plasma, as well as the total pressure. The intervals when the dynamic pressure exceeded the solar wind dynamic pressure $(1 \mathrm{nPa})$ are shaded in grey. Panel (a) is adapted from Hietala et al. (2009).

The observations of $\mathrm{C} 3$ (not shown) are similar, though not identical to $\mathrm{C} 1$. Given this and the fact that $\mathrm{C} 2$ was outside of the jet when the other satellites were inside of it (see Fig. 4), we infer that the lower limit for the size of the jet was of the order of the spacecraft separation $\left(\sim 8000 \mathrm{~km}, 1.2 R_{\mathrm{E}}\right)$.

\subsubsection{Pressure pulses and magnetopause perturbations}

Let us then consider the magnetosheath properties during the period of steady solar wind conditions from 17:00 to 20:20 UT. The top panel of Fig. 6 displays the ACE observations for reference. The bottom panels show Cluster 1 measurements: omni-directional ion energy spectrograms, ion velocity, magnetosonic Mach number $\left(V / V_{\mathrm{MS}}\right)$, and pressure. As is best seen from the ion energies (Fig. 6b), the magnetopause moved over the spacecraft several times; the high energy and low density intervals of magnetospheric plasma alternate with the intervals of high density magnetosheath flow.

Figure $6 \mathrm{c}$ and $\mathrm{d}$ with the $\mathrm{C} 1$ velocity observations show that the magnetosheath plasma motion was highly varying. There were many supermagnetosonic jets (blue intervals) with the local $M_{\mathrm{MS}} \gtrsim 1.5$, and the one near 18:15 UT as high as $M_{\mathrm{MS}} \sim 2.5$. Using $-V_{\mathrm{X}}$ instead of $V$ in the characterisation of the jets would not result in significant differences: at 17:15 and 17:25 UT, $V / V_{\mathrm{MS}}$ was close to 1 but the main contribution came from $V_{Z}$. At 18:10 UT, the flow was in fact sunward $\left(V_{X}>0\right)$. We thus conclude that the main contribution to the jet speed comes from $V_{X}$, but the deflection $\left(V_{Y}\right.$ and $V_{Z}$ ) varies from one jet to another.

Spectrograms (Fig. 6b) suggest that during a jet there were typically less low energy particles than in the subsonic magnetosheath. However, this is probably just an artefact of measuring the particles in the frame of reference of the 
spacecraft. In some cases, there were also less high energy particles, e.g., at 18:15, 18:50, and 19:55 UT. This, on the contrary, is an indication of a (locally) quasi-perpendicular bow shock.

There is a clear connection between the magnetopause crossings and the supermagnetosonic jets: an inward motion of the magnetopause was typically followed by a jet with large negative $V_{\mathrm{X}}$. Note that these jets attained their maximum speed about a minute after the magnetopause crossing, i.e., well within the magnetosheath. In addition, some outward motions of the magnetopause, for example near 18:10 UT, were preceded by sunward flow. This can be interpreted as the magnetopause pushing the plasma in front of itself.

The more precise cause of these magnetopause perturbations was the high dynamic pressure of the jets, in agreement with the propositions of Sect. 2: Fig. 6e displays the C1 pressure observations. The grey intervals, when the magnetosheath dynamic pressure locally exceeded the upstream value of $1 \mathrm{nPa}$, match well with the blue intervals of supermagnetosonic flow. Most of the jets had a dynamic pressure between two and four times the solar wind value, in agreement with Eq. (2). In a few cases, the pressure was as high as 5 to $7 \mathrm{nPa}$. These extreme pulses coincided with density increases, possibly caused by convergence of the flow coming from different parts of the ripple (see Fig. 1c). The dynamic pressure in the magnetosheath outside the jets was less than the solar wind dynamic pressure, as expected, and the thermal pressure $P_{\mathrm{T}}$ dominated. It is thus natural to conclude that the jets pushed the magnetopause past the spacecraft and perturbed it locally.

There are at least four possible sources for high speed jets in the magnetosheath. The ACE observations (Fig. 6a) show that, during the period under consideration, there were small fluctuations in the interplanetary magnetic field direction, and three excursions of $\sim 40^{\circ}$. It is of course possible that some of the jets were related to these variations, but we find it unlikely that all of them were triggered by such small changes. Magnetopause reconnection exhaust jets with predominant $-X$ directions are unlikely this close to the nose, and during radial IMF. Such exhaust jets would also be detected simultaneously with or very close to magnetopause crossings and grazings. On the contrary, the jets presented here were observed well on the magnetosheath side, and two of them (at 18:32 and 19:53) were observed in fact without any magnetopause signature in proximity. Turbulent reconnection of thin current sheets in the quasi-parallel magnetosheath (Retinò et al., 2007) in these conditions is possible, but the time scale of many of the now observed jets (up to few minutes) would correspond to implausibly large currents sheets. We would also expect the direction of such jets to be more random. The dominant $-X$ direction with a varying deflection, the average dynamic pressure and the ion energy characteristics of the jets support the mechanism proposed by Hietala et al. (2009), i.e., that the fluctuations in the tur- bulent foreshock interacted with the bow shock and induced ripples that locally focused the flow into the high speed jets.

\subsection{Magnetosphere: GOES-11 and 12 observations}

The effects of the local pressure pulses that deform the magnetopause are transmitted into the magnetosphere. Indentations of the magnetopause should result in increases of the magnetic field strength as the magnetophere is compressed. In this subsection, we consider magnetic field data from the geostationary GOES-11 and 12 satellites.

Figure 7 shows the magnetic pressure observed by the two spacecraft from 12:00 to 22:00 UT (magenta and cyan curves). The pressure of the pure dipole field has been removed using the GEOPACK library by N. Tsyganenko. Accordingly, the displayed deviations result solely from the external (solar wind and magnetosheath) driving. The ACE upstream solar wind observations (Fig. 7a) are shown again for reference.

First, we can see that the general trends in the data follow the motion of the spacecraft (Fig. 2). GOES-11 was moving from the nightside to the dayside, and observed an increasing magnetic pressure (Fig. 7b). GOES-12 was crossing the dayside and measured an increase followed by a decrease of the magnetic pressure (Fig. 7c). However, the field on the dayside was quite dipolar, i.e., the average deviation was only slightly positive. This is consistent with the low solar wind dynamic pressure and the radial IMF direction (see, e.g., Suvorova et al., 2010). As the IMF direction changed around 20:20 UT, the deviation observed by GOES-11 near the subsolar point reached a steady level of $1 \mathrm{nPa}$ - a significantly higher magnetic pressure than GOES-12 observed at the same location, on average.

Next, the observations display sharp, irregular pulsations, in the time scale of a few minutes. The pulsations seem to be related to the quasi-radial IMF: at GOES-12 they began around 12:40 UT, when the average IMF direction had become radial and the spacecraft was moving to the dayside (magnetic local time $7.6 \mathrm{~h}$ ). GOES-11 started to observe them after 17:25 UT, when it reached a similar location (magnetic local time $8.2 \mathrm{~h}$ ). The pulsations ended at both spacecraft when the IMF turned near 20:20 UT. This remark suggests a connection to the quasi-parallel bow shock. It also agrees with previous observations of quiet time geosynchronous magnetic field oscillations at the pre-noon and postnoon sectors for spiral and orthospiral IMF configurations (Sanny et al., 2002).

Another important feature of the pulsation data is the lack of similarity between the two satellites' observations: an increase measured by one is not always accompanied by increase at the other at the same time.

Together with the GOES measurements we show the dynamic pressure at $\mathrm{C} 1$ (black) and $\mathrm{C} 3$ (green) in order to indicate the Cluster jet observations: the intervals when the dynamic pressure at $\mathrm{C} 1$ or $\mathrm{C} 3$ exceeded the solar wind 


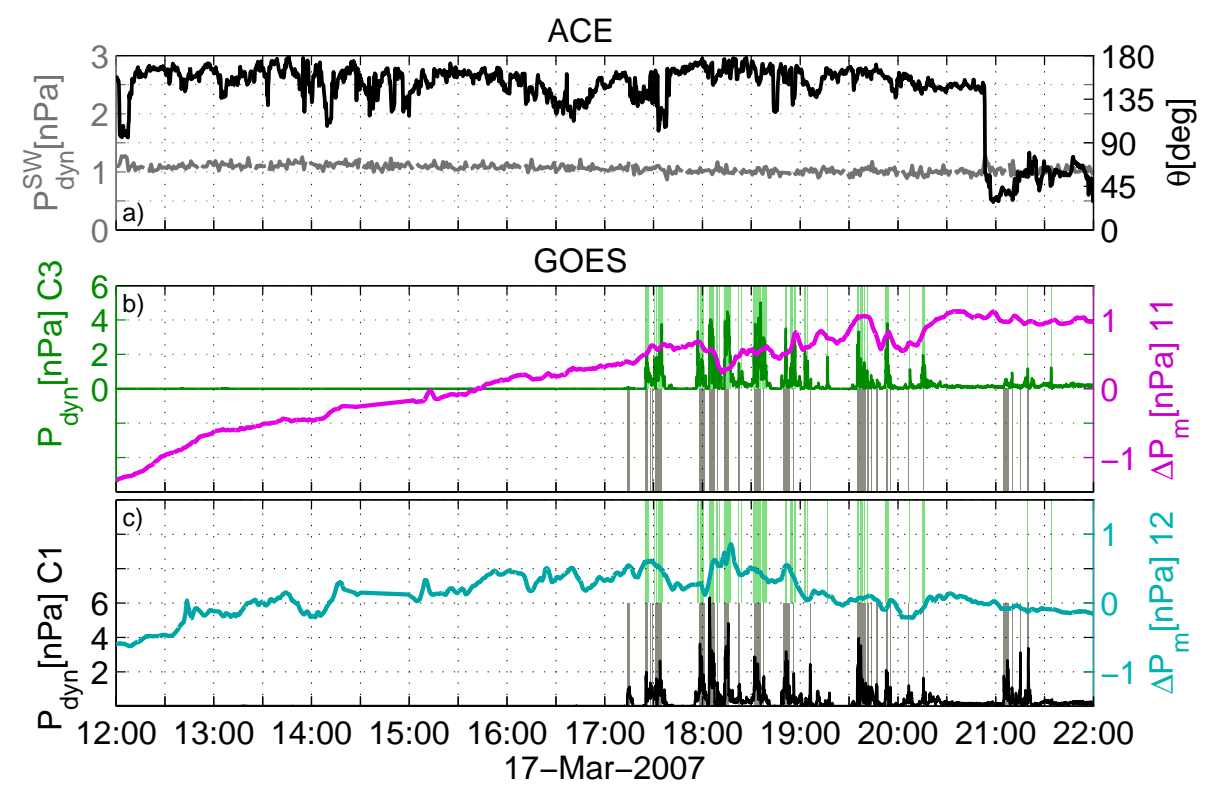

Fig. 7. (a) ACE observations (time-shifted by $44 \mathrm{~min}$ ) of the angle $\theta$ between the IMF direction vector and the $X_{\mathrm{GSE}}$-axis and of the solar wind dynamic pressure. (b, c) GOES-11 (magenta) and GOES-12 (cyan) magnetic pressure observations in the magnetosphere in 1-min time resolution. The pressure of the pure dipole field has been removed using the GEOPACK library by N. Tsyganenko. The dynamic pressure at $\mathrm{C} 1$ (black) and C3 (green) are displayed in order to indicate the Cluster jet observations. The intervals when the dynamic pressure at $\mathrm{C} 1$ (C3) exceeded the solar wind dynamic pressure are in shaded grey (green).

dynamic pressure $(1 \mathrm{nPa})$ are highlighted with the corresponding colour. The magnitude of the dynamic pressure is naturally an indication of the strength of the jet impinging on the magnetosphere. Note that the last jet observations shortly after 21:00 UT were probably related to the changes in the IMF configuration (Fig. 7a). During the period of interest, from 17:00 to 20:30 UT, both GOES satellites were located on the dayside. Moreover, GOES-12 was approximately between the Earth and Cluster during the beginning of the interval, while GOES-11 moved to a location between the Earth and the quartet near the end of the interval (Fig. 2).

We see that there was no one-to-one correspondence between the jets observed by $\mathrm{C} 1$ and $\mathrm{C} 3$ and the pulsations, neither in time nor in strength. However, GOES-12 observed pressure increases near the jets around 17:30, and 18:10 UT (maybe also at 17:15 UT) when it was in the same local time sector as Cluster. There were no significant increases at GOES-11 and, near 18:10 UT, it in fact measured a decrease. Similarly, GOES-11 observed increases near the jets at 19:40 UT when it had moved to a location earthward of Cluster, while GOES-12 did not see a significant increase. The jets near 18:50 UT were accompanied by an increase at both satellites, although with a delay at GOES-11, as they were at an approximately equal distance away. On the other hand, there were observations that did not follow this pattern: the jets around 18:35 UT were not accompanied by significant pulsations in either of the magnetospheric satellites, while the short jets at 19:50 UT seemed to be related to pulsations observed by both.
A similar yet complementary picture rises when comparing the GOES observations with the Cluster magnetic field strength measurements (not shown). Namely, we examined the alternation of the intervals of high and stable $B$ (Cluster in the magnetosphere), with the intervals of lower and fluctuating $B$ (Cluster in the magnetosheath). A locally contracted magnetosphere at Cluster's location corresponded quite well, though not always, with a GOES pressure increase and an expanded magnetosphere with a decrease. This similarity of conclusions is natural since, according to the analysis of the previous subsection, the jets seemed to be the cause of the magnetopause perturbations.

Given the $\sim 40000 \mathrm{~km}$ distance between the GOES satellites, we conclude that it is unlikely that the supermagnetosonic jets were very large, coherent structures. As the pulsations that could be related to a jet were typically observed only by the satellite that was closest to the time sector of Cluster, and not by the other, the approximately $6 R_{\mathrm{E}}$ separation presents an upper limit to the jet's transverse size. Naturally some jets were much smaller than this, for instance some were observed only by a single Cluster spacecraft (Fig. 7). This also explains why the jets near 18:35 UT were missed by both GOES satellites. Furthermore, the small magnitude of the observed pulsations agrees with the inferred scale: the effects of very localised pressure pulses should weaken quite fast as they are transmitted deeper into the magnetosphere. 


\subsection{Ionosphere: SuperDARN observations}

The day of interest, 17 March 2007, was magnetically quiet, especially in the UT afternoon. According to the global Auroral Electrojet (AE) index, three periods of activity were recorded between 13:00 UT and midnight. During these activations at around 16:30, 17:45 and 20:00 UT, the AE varied in the range of $100-300 \mathrm{nT}$. These periods of activity coincided with northward turnings of the IMF $B_{\mathrm{Z}}$ and are, thus, more likely signatures of changing solar wind energy input into the magnetosphere-ionosphere system due to varying large-scale reconnection rate rather than related to the mesoscale magnetopause perturbations.

To investigate the ionospheric response to the jets in the magnetosheath, we examine ionospheric flow velocities measured by the Super Dual Auroral Radar Network. In 2007 ten SuperDARN radars were in use on the Northern Hemisphere. Each radar emits high-frequency (HF) pulses that reflect off decameter-scale density perturbations in the ionosphere. These irregularities move with the background bulk plasma motion and the SuperDARN radars hence measure the line-of-sight component of the ionospheric $\boldsymbol{E} \times \boldsymbol{B}$ drift. An expansion of spherical harmonics can be fitted to the combined line-of-sight velocities from all available radars to produce hemispheric convection patterns (Ruohoniemi and Baker, 1998). These convection maps are created every two minutes.

Since there was also other activity, we are unable to fully isolate the effect of the magnetosheath jets to form a clear relationship between the magnetosheath and ionospheric flows. On the other hand, given the GOES magnetospheric observations indicating a small spatial scale (discussed in the previous subsection), a distinct correspondence is not expected. However, during the time period of radial IMF and high pressure jets, multiple localised short-lived flow channels of enhanced convection were observed in the dayside polar ionosphere.

An example of enhanced convection is presented in Fig. 8, where six convection patterns are displayed between 18:18 and 18:30 UT. The convection patterns are plotted in magnetic coordinates and the Sun is to the top of each panel. During this time period, the IMF $B_{\mathrm{Z}}$ was slightly positive $(\sim+1 \mathrm{nT})$ and $B_{X}$ still strongly dominating $(\sim-3 \mathrm{nT})$. The high speed flow started to appear at 18:20 UT (Fig. 8b) in the region just northwest of Hudson Bay. Two minutes later (Fig. 8c) the flow channel had expanded southward, and the fit also indicates development of a counterclockwise flow vortex. The flow channel was at its widest at 18:24UT (Fig. 8d) and started to shrink during the next 2-min interval (Fig. 8e). At 18:28 UT the flow signature had disappeared. The maximum flow speed exceeded $1000 \mathrm{~m} \mathrm{~s}^{-1}$ during the lifetime of the burst from 18:20 to 18:26 UT.

During the lifetime of the flow channel the number of data points, indicated by the $n_{\mathrm{vc}}$ in each panel, was 60-100, which is quite low. However, the coverage at and around the inter- esting region was good. The velocity at the interesting area was also large compared to the observed surroundings. Furthermore, the velocity vectors behave coherently as functions of time, i.e., there was a smooth enhancement and decay. Thus we conclude that the radar data are reliable enough for a qualitative picture and we infer that this flow channel was a potential ionospheric counterpart of the jets.

To better understand this possible connection, we examine the measurements of the SuperDARN radar located near Kapuskasing, Canada. From the returned signal the radar produces the backscattered power, the Doppler velocity of the scatter target and its spectral width. Furthermore, the look direction of the radar can be electronically steered along 16 beams; these beams are each $3.24^{\circ}$ wide and it takes the radar $2 \mathrm{~min}$ to make measurements along all 16 beams.

In the panels (b-d) of Fig. 9 we show the three parameters measured along beam 8 that is looking approximately due magnetic North. In the figure time runs along the x-axis, whereas the $y$-axis gives the distance from the radar. All parameters are colour-coded according to the colour scales to the right of the plot; in the SuperDARN convention negative velocities denote motion away from the radar (red), whereas positive velocities indicate motion towards the radar (blue). Velocities between -50 and $+50 \mathrm{~m} \mathrm{~s}^{-1}$ have been coloured grey. These very low velocities are, at high-latitudes, caused by HF radio waves that are refracted by the ionosphere and then reflected off the ground; this ground scatter contains no information about the ionospheric bulk plasma motion.

The time interval shown in Fig. 9 corresponds to that of Cluster jet observations, and the magnetosheath dynamic pressure measured by $\mathrm{C} 1$ and $\mathrm{C} 3$ is shown in Fig. 9a. The nine main jets observed by $\mathrm{C} 1$ are marked by vertical dashed lines in the lower panels. During the entire interval a stable band of ground scatter persisted between range gates 25 and 35. Poleward of this ground scatter band the radar observed two to four short-lived (between 2 and $12 \mathrm{~min}$ ) bursts of higher velocities, marked by the red arrows. These bursts, located at around $75^{\circ}$ magnetic latitude and magnetic noon, were directed away from the radar and had velocities of about $700 \mathrm{~m} \mathrm{~s}^{-1}$. Their spectral width had values below $200 \mathrm{~m} \mathrm{~s}^{-1}$ and the backscattered power was relatively low, below $10 \mathrm{~dB}$.

These ionospheric velocity bursts, located near the ionospheric foot print of the cusp region, all occured about $5 \mathrm{~min}$ after a jet was observed in the subsolar magnetosheath by Cluster. Both the spatial proximity and the reasonable time delay between the two events suggest that these ionospheric bursts were caused by the magnetosheath jets.

We have also examined the magnetometers located under the Kapuskasing radar field-of-view, namely Taloyoak (TALO) station of the Canadian Array for Realtime Investigations of Magnetic Activity (CARISMA) chain ja Resolute (RES) station of the Canadian Magnetometer Observatory Network (CANMOS) chain (not shown). The magnetometer data show some 50-100 nT perturbations in $B_{\mathrm{X}}$ and $B_{\mathrm{Y}}$ occuring after the magnetosheath jets in agreement with 

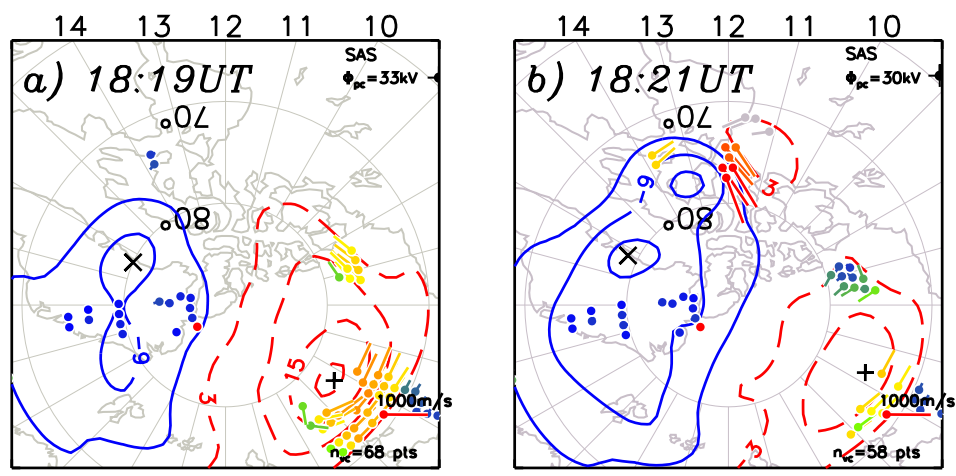

$-\begin{aligned} & 875 \\ & 750\end{aligned}$
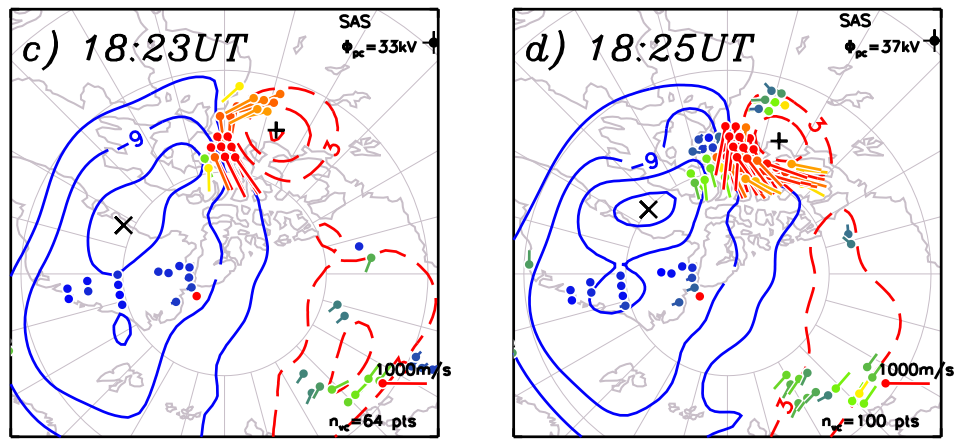

$\mid \begin{array}{r}625 \frac{-}{1} \\ 500 \frac{E}{\frac{\pi}{4}} \\ 375 \stackrel{\frac{0}{0}}{>}\end{array}$
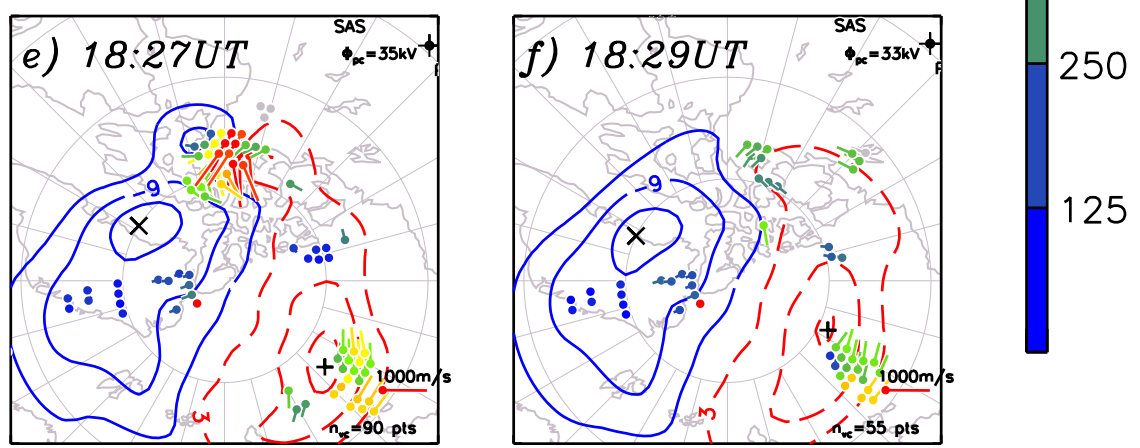

Fig. 8. Ionospheric convection pattern fitted into the SuperDARN measurements. The maps are in magnetic coordinates and the Sun is to the top, dawn to the right, and dusk to the left in each panel. The maps represent the flow pattern with 2-min integration time at (a) 18:1818:20, (b) 18:20-18:22, (c) 18:22-18:24, (d) 18:24-18:26, (e) 18:26-18:28 and (f) 18:28-18:30 UT. During an otherwise quiet period and positive IMF $B_{\mathrm{Z}}$, a short-lived channel of fast flow up to $1000 \mathrm{~m} \mathrm{~s}^{-1}$ (red vectors) was observed on the dayside following the fast flows in the magnetosheath.

the radar observations. The strength of these perturbations is typical for mesoscale dayside variations (e.g., Kataoka et al., 2001, 2003).

\section{Discussion}

Quasi-radial direction is not a rare configuration for the interplanetary magnetic field. According to a statistical study of $11 \mathrm{yr}$ of ACE data by Suvorova et al. (2010), conditions with the cone angle $\theta<30^{\circ}$ occur about $16 \%$ of the time. In particular, radial IMF is quite a common feature at the trailing edge of a magnetic cloud resulting from a coronal mass ejection. Neugebauer et al. (1997) reported that approx- imately one fifth of these events contain long ( $\geq 6 \mathrm{~h}$ ) periods of steady, radial IMF conditions. This was not the case in the event discussed here: 2007 was a year of the deep solar minimum at the end of cycle 23. A stream interaction region, however, crossed the near-Earth space on 11 March resulting in the declining trend in the solar wind speed observed still on 17 March.

As pointed out in Sect. 1, the bow shock and its surroundings are greatly affected by the radial IMF configuration. Since the magnetic field is aligned with the solar wind flow, the turbulent foreshock of the quasi-parallel bow shock covers the whole dayside. The effects of radial IMF are displayed most vividly in the $2.5 \mathrm{D}$ hybrid simulations by Sibeck et al. (2008), Blanco-Cano et al. (2009), and 

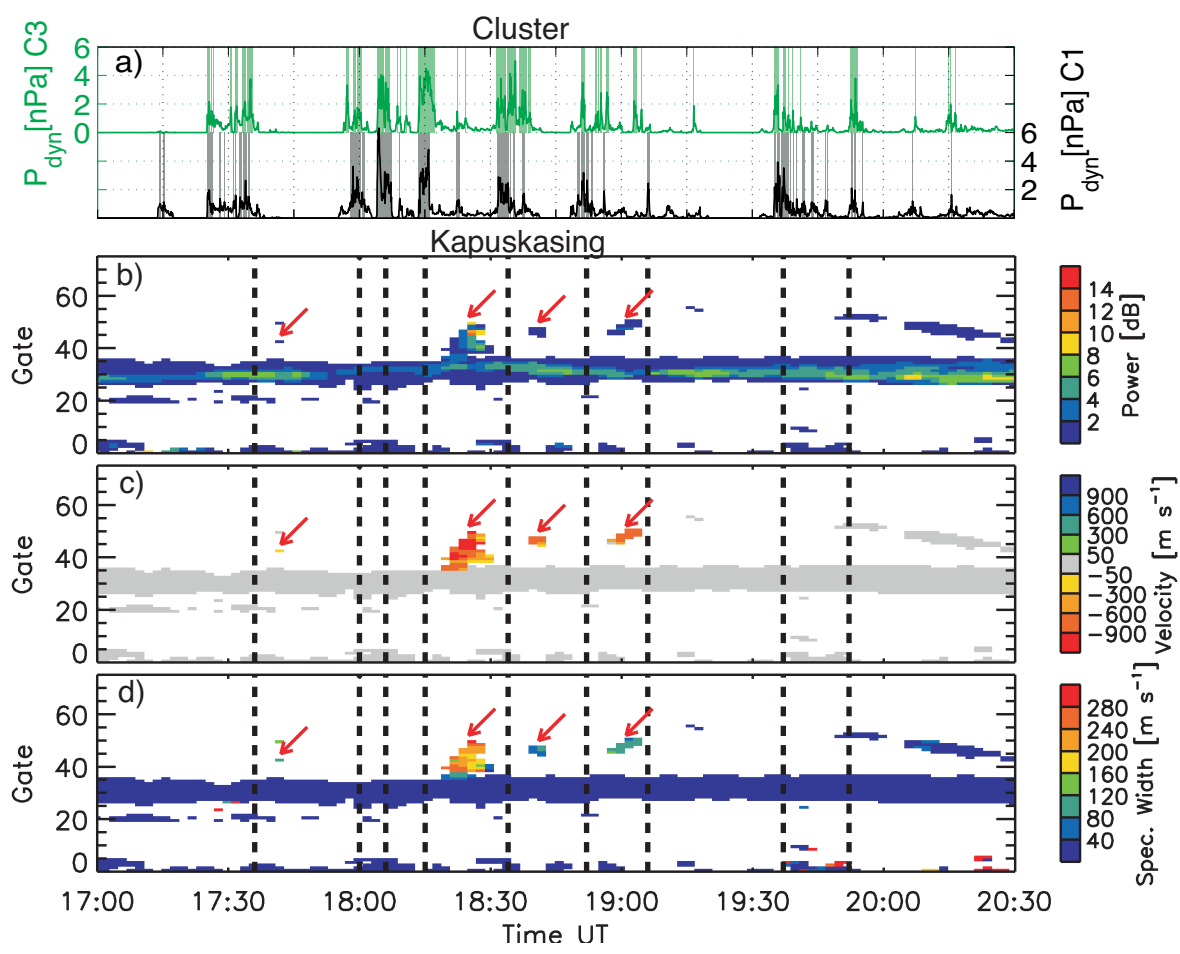

Fig. 9. (a) C1 (black) and C3 (green) magnetosheath dynamic pressure observations. The intervals when the local dynamic pressure exceeded the solar wind dynamic pressure are shaded. Lower panels: SuperDARN Kapuskasing radar observations. The panels show rangetime plots of (b) backscattered power, (c) ionospheric velocity and (d) spectral width measured along beam 8 of the radar. The data have been median-filtered to remove salt-and-pepper noise. Vertical dashed lines mark the nine main supermagnetosonic jets observed by $\mathrm{C} 1$. The red arrows identify enhanced ionospheric flows.

Omidi et al. (2009). There are also observations that show that during radial IMF the bow shock is closer to the Earth than predicted by the models (see Merka et al., 2003, and references therein).

The magnetosheath downstream of the quasi-parallel shock is permeated both by waves that have been transmitted through the bow shock, as well as by fluctuations that have been generated locally. Statistical studies (Shevyrev and Zastenker, 2005; Shevyrev et al., 2007) show that the quasiparallel magnetosheath is very turbulent even during steady solar wind conditions. For the radial IMF case, Blanco-Cano et al. (2006) have reported large amplitude fluctuations also on the downstream side in their hybrid simulations.

In previous magnetosheath studies, Savin et al. (2008) and Amata et al. (2011) have found several jets with high kinetic energy density at the magnetospheric flanks, while Shue et al. (2009) reported a similar high speed flow near the subsolar point. Nemecek et al. (1998) have also reported on what they call transient ion flux enhancements at the flanks, mainly when the plasma entered through the foreshock region. These previous studies could not identify a clear source for the jets, but they could rule out, e.g., reconnection. Naturally, it is not possible to ascertain that all previously reported jets stem from the shock ripple-related mechanism proposed by Hietala et al. (2009). Still, both transient flux enhancements and high kinetic energy jets have properties similar to the jets reported here. In particular, they have been observed behind the quasi-parallel bow shock, especially during intervals of radial IMF.

The GOES observations of pulsations presented in this article (Fig. $7 b$ and c) suggest that the high speed jets could be occuring across the whole dayside magnetosheath during the period of radial IMF (see also Sanny et al., 2002). This would be consistent with the proposed formation mechanism based on quasi-parallel shock ripples. In that case, the jets would be one of the downstream manifestations of the upstream foreshock fluctuations that modify the shock transition, i.e., of the "patchwork" shock (e.g., Schwartz and Burgess, 1991). It thus seems probable that the jets are equally dynamic varying in both space and time. Note, however, that at the flanks of the magnetosphere, the magnetosheath flow is supermagnetosonic on average. Consequently, the ripples at the flanks would not necessarily create easily discernible jets but rather contribute to the overall downstream variability. Hence it is important to concentrate on the subsolar region when investigating the effects of the ripples and the jets.

During the period under study, Cluster observed magnetopause crossings at several places that deviated from the 
Shue et al. (1998) magnetopause model by more than $1 R_{\mathrm{E}}$ (Fig. 2). These perturbations are not surprising given the observed total pressure (the sum of dynamic, magnetic and thermal pressures) variations in the magnetosheath (see also Glassmeier et al., 2008). Detailed studies of single magnetopause perturbations due to high speed jets have previously been done by Shue et al. (2009) and Amata et al. (2011) using THEMIS and Cluster observations. The estimated size of the magnetopause indentation in both cases was of the same order as in the event presented here.

Other studies have also built up evidence of the overall perturbed state of the magnetopause behind quasi-parallel bow shock. Russell et al. (1997) reported enhanced magnetopause oscillations behind the quasi-parallel bow shock in the dawn sector using $10 \mathrm{yr}$ of data from ISEE-1 and 2. Suvorova et al. (2010) described subsolar magnetopause wavy motion and expansion during three intervals of radial IMF, but they did not present dynamic pressure data. In a recent statistical study using THEMIS data, Plaschke et al. (2009) examined magnetopause oscillations at fundamental frequencies during different solar wind conditions, and found that radial IMF is among the favorable conditions.

Although we find magnetopause reconnection very unlikely as the cause of the high speed jets (Sect. 3.2.2), local, small-scale magnetopause reconnection as a consequence would not be surprising. Indeed, it is quite plausible that the high dynamic pressure jets directed at the magnetopause and perturbing it may also trigger reconnection events there. The ionospheric observations are consistent with this as well.

Sibeck et al. (1989) studied magnetospheric response to brief upstream pressure variations $\left(\Delta P_{\mathrm{dyn}} / P_{\mathrm{dyn}}=1\right.$, $P_{\text {dyn }} \sim 1.2 \mathrm{nPa}$ ) during radial IMF (see also Fairfield et al., 1990). They used simultaneous observations just upstream of the Earth's bow shock as well as from three magnetospheric satellites, including GOES-6. The upstream pressure variations were associated with compressional oscillations in the dayside magnetosphere that were similar to the ones reported here.

Still, there were no satellites in the magnetosheath at that time, so Sibeck et al. (1989) could not study how the pressure variations were transmitted from the upstream into the magnetosphere. The formation of bow shock ripples provides a mechanism to enhance these upstream variations. The ripple induced jets are then a means to transmit the variations through the magnetosheath and affect the magnetopause, as seen in Sect. 3.

The stepwise increases around 18:10 UT at GOES-12 (Fig. 7c) indicate that the jets may have a cumulative effect: several intense jets at the same location created the strongest magnetospheric response. As the jets in this particular event often occurred less than ten minutes apart, it is likely that the magnetosphere did not have enough time to recover from every burst.

Another prominent feature of the GOES observations near 18:10 UT is the anti-correlation between the two spacecraft.
There was a simultaneous decrease of pressure at GOES-11 and an increase of pressure at GOES-12 that was slightly duskward from C1/C3. Such a behaviour could be interpreted as magnetosphere being compressed in one place and expanding in another. This interpretation is supported by the fact that $\mathrm{C} 2$, which was closer to GOES-11, moved into the magnetosphere (Fig. 4) at the time.

We have shown that some of the magnetosheath jets observed by Cluster near the subsolar point were followed by plasma velocity bursts in the polar ionosphere. These ionospheric velocity features were short-lived (on average about $5 \mathrm{~min}$ ) and localised. Their morphology is similar to the ionospheric signature of Flux Transfer Events (FTEs) (McWilliams et al., 2004). However, FTEs predominantly take place under upstream conditions other than radial IMF (e.g., Kawano and Russell, 1997). Furthermore, typical radar signatures of FTEs are high backscattered power $(>24 \mathrm{~dB})$ and high spectral width (Provan et al., 1998), both of which were lower during the events discussed here. It thus seems more likely that the magnetosheath jets caused particles to precipitate along closed field-lines just inside of the magnetopause into the polar ionosphere. There they temporarily formed density irregularities for the duration of the jet, off which the HF signal was scattered, and enabled the radar observations of the ionospheric flow velocities at the magnetic foot point of the magnetosheath jets.

Pressure variations creating magnetopause perturbations can also drive ionospheric flows (e.g., Kivelson and Southwood, 1991). Furthermore, they are one of the mechanisms for the generation of ionospheric Travelling Convection Vortices (TCVs). TCVs and the related Magnetic Impulse Events (MIEs) have several properties (Kataoka et al., 2001, 2003) in common with the ionopheric flow enhancements reported here: They have similar maximum ionospheric velocities, magnetic latitudes, and spatial scales; their lifetimes are similar (about ten minutes), though flow channels are somewhat more short-lived; the corresponding horizontal magnetic field variations have similar magnitudes (few tens of nTs to one hundred); during the events the activity level described by the Kp index is low; and the IMF $B_{Z}$ is positive. Moreover, according to statistical studies (e.g., Sibeck and Korotova, 1996; Kataoka et al., 2003) the MIE/TCV occurrence has a preference for radial IMF orientation. For all that, the flow channels described in the present paper do not show a tendency to travel.

\section{Summary and conclusions}

We have used simultaneous solar wind, magnetosheath, magnetosphere, and ionosphere observations to study the solar wind-magnetosphere interaction during a period of steady radial IMF. We have concentrated on the supermagnetosonic jets observed in the subsolar magnetosheath, and investigated how their effects are transmitted into the magnetosphere. Our 
analysis of the jets showed that their properties are in agreement with the previous proposition (Hietala et al., 2009) that they are formed by ripples inherent to the quasi-parallel bow shock. We concluded that some of the jets in this event were as large as 1-3 $R_{\mathrm{E}}$, but typically smaller than $\sim 6 R_{\mathrm{E}}$. These intermittent pulses of dynamic pressure created magnetopause perturbations and thus provided a source for magnetopause waves during steady solar wind conditions. Further, we inferred that the patchy pressure pulses propagated into the magnetosphere and were detectable at the geostationary orbit. In the ionosphere we identified localised and shortlived enhanced convection flow channels. Their location and timing suggest that they were caused by the magnetosheath jets.

The suggested connection between the magnetosheath jets and the ionospheric flow enhancements requires further, preferably statistical studies. Potential topics for future analysis include: the time delay between a jet and its ionospheric signature; the possible correlation between their strengths and lifetimes; and the possible connection between the MIEs/TCVs and the high speed jets. Incorporation of magnetosheath and ground-based observations is indispensable for such studies.

Acknowledgements. We thank CDAWeb at NSSDC and the Cluster Active Archive for data access. We thank the Cluster FGM, EFW, CIS, and PEACE instrument teams for their data. We also thank N. Ness and D. J. McComas for the ACE data, T. Mukai and T. Nagai for the Geotail data, and H. J. Singer for the GOES data. CARISMA (TALO) and CANMOS (RES) data were downloaded from the Canadian Space Science Data Portal https://cssdp.ca. We thank both magnetometer network teams. H. H. would like to thank R. Vainio, T. Pulkkinen, and M. Palmroth for fruitful discussions. The Väisälä foundation, the M. Ehrnrooth foundation, and the Academy of Finland are thanked for financial support. L. B. N. C. acknowledges funding from the National Science Foundation under grant number ATM-0924919. G. F. was supported by the OTKA Grant K75640 of the Hungarian Scientific Research Fund.

Topical Editor R. Nakamura thanks D. Sibeck and two other anonymous referees for their help in evaluating this paper.

\section{References}

Acuña, M. H., Ogilvie, K. W., Baker, D. N., Curtis, S. A., Fairfield, D. H., and Mish, W. H.: The Global Geospace Science Program and Its Investigations, Space Sci. Rev., 71, 5-21, 1995.

Amata, E., Savin, S. P., Ambrosino, D., Bogdanova, Y. V., Marcucci, M. F., Romanov, S., and Skalsky, A.: High kinetic energy density jets in the Earth's magnetosheath: A case study, Planet. Space Sci., 59, 482-494, 2011.

Angelopoulos, V.: The THEMIS mission, Space Sci. Rev., 141, 534, 2008.

Asbridge, J. R., Bame, S. J., and Strong, I. B.: Outward Flow of Protons from the Earth's Bow Shock, J. Geophys. Res., 73, 5777$5782,1968$.
Balogh, A., Carr, C. M., Acuña, M. H., Dunlop, M. W., Beek, T. J., Brown, P., Fornacon, K.-H., Georgescu, E., Glassmeier, K.H., Harris, J., Musmann, G., Oddy, T., and Schwingenschuh, K.: The Cluster Magnetic Field Investigation: overview of in-flight performance and initial results, Ann. Geophys., 19, 1207-1217, doi:10.5194/angeo-19-1207-2001, 2001.

Blanco-Cano, X., Omidi, N., and Russell, C. T.: ULF waves and their influence on bow shock and magnetosheath structures, Adv. Space Res., 37, 1522-1531, 2006.

Blanco-Cano, X., Omidi, N., and Russell, C. T.: Global hybrid simulations: Foreshock waves and cavitons under radial interplanetary magnetic field geometry, J. Geophys. Res., 114, A01216, doi:10.1029/2008JA013406, 2009.

Burgess, D., Lucek, E. A., Scholer, M., Bale, S. D., Balikhin, M. A., Balogh, A., Horbury, T. S., Krasnoselskikh, V. V., Kucharek, H., Lembège, B., Mobius, E., Schwartz, S. J., Thomsen, M. F., and Walker, S. N.: Quasi-parallel Shock Structure and Processes, Space Sc. Rev., 118, 205-222, 2005.

Chisham, G., Lester, M., Milan, S. E., Freeman, M. P., Bristow, W. A., Grocott, A., McWilliams, K. A., Ruohoniemi, J. M., Yeoman, T. K., Dyson, P. L., Greenwald, R. A., Kikuchi, T., Pinnock, M., Rash, J. P. S., Sato, N., Sofko, G. J., Villain, J.-P., and Walker, A. D. M.: A decade of the Super Dual Auroral Radar Network (SuperDARN): Scientific achievements, new techniques and future directions, Surv. Geophys., 28, 33-109, 2007.

Escoubet, C. P., Schmidt, R., and Goldstein, M. L.: Cluster - science and mission overview, Space Sci. Rev., 79, 11-32, 1997.

Fairfield, D. H., Baumjohann, W., Paschmann, G., Lühr, H., and Sibeck, D. G.: Upstream Pressure Variations Associated with the Bow Shock and their Effects on the Magnetosphere, J. Geophys. Res., 95, 3773-3786, 1990.

Glassmeier, K.-H., Auster, H.-U., Constantinescu, D., Fornaçon, K.-H., Narita, Y., Plaschke, F., Angelopoulos, V., Georgescu, E., Baumjohann, W., Magnes, W., Nakamura, R., Carlson, C. W., Frey, S., McFadden, J. P., Phan, T., Mann, I., Rae, I. J., and Vogt, J.: Magnetospheric quasi-static response to the dynamic magnetosheath: A THEMIS case study, Geophys. Res. Lett., 35, L17S01, doi:10.1029/2008GL033469, 2008.

Gosling, J. T., Thomsen, M. F., Bame, S. J., and Russell, C. T.: Ion Reflection and Downstream Thermalization at the Quasi-Parallel Bow Shock, J. Geophys. Res., 94, 10027-10037, 1989.

Greenstadt, E. W., Hoppe, M. M., and Russell, C. T.: Large amplitude magnetic variations in quasi-parallel shocks: Correlation lengths measured by ISEE 1 and 2, Geophys. Res. Lett., 9, 781784, 1982.

Greenwald, R. A., Baker, K. B., Dudeney, J. R., Pinnock, M., Jones, T. B., Thomas, E. C., Villain, J.-P., Cerisier, J.-C., Senior, C., Hanuise, C., Hunsucker, R. D., Sofko, G., Koehler, J., Nielsen, E., Pellinen, R., Walker, A. D. M., Sato, N., and Yamagishi, H.: DARN/SuperDARN, A global view of the dynamics of highlatitude convection, Space Sci. Rev., 71, 761-796, 1995.

Grubb, R. N.: The SMS/GOES space environment monitor subsystem, NOAA Tech. Memo., ERL SEL-42, 1975.

Gustafsson, G., Bostrom, R., Holback, B., Holmgren, G., Lundgren, A., Stasiewicz, K., Ahlen, L., Mozer, F. S., Pankow, D., Harvey, P., Berg, P., Ulrich, R., Pedersen, A., Schmidt, R., Butler, A., Fransen, A. W. C., Klinge, D., Thomsen, M., Falthammar, C.-G., Lindqvist, P.-A., Christenson, S., Holtet, J., Lybekk, B., Sten, T. A., Tanskanen, P., Lappalainen, K., and Wygant, J.: 
The Electric Field and Wave Experiment for the Cluster Mission, Space Sci. Rev., 79, 137-156, 1997.

Hietala, H., Laitinen, T. V., Andréeová, K., Vainio, R., Vaivads, A., Palmroth, M., Pulkkinen, T. I., Koskinen, H. E. J., Lucek, E. A., and Rème, H.: Supermagnetosonic Jets behind a Collisionless Quasiparallel Shock, Phys. Rev. Lett., 103, 245001, doi:10.1103/PhysRevLett.103.245001, 2009.

Johnstone, A. D., Alsop, C., Burge, S., Carter, P. J., Coates, A. J., Coker, A. J., Fazakerley, A. N., Grande, M., Gowen, R. A., Gurgiolo, C., Hancock, B. K., Narheim, B., Preece, A., Sheather, P. H., Winningham, J. D., and Woodliffe, R. D.: Peace: a Plasma Electron and Current Experiment, Space Sci. Rev., 79, 351-398, 1997.

Kataoka, R., Fukunishi, H., Lanzerotti, L. J., Maclennan, C. G., Frey, H. U., Mende, S. B., Doolittle, J. H., Rosenberg, T. J., and Weatherwax, A. T.: Magnetic impulse event: A detailed case study of extended ground and space observations, J. Geophys. Res., 106, 25873-25890, 2001.

Kataoka, R., Fukunishi, H., and Lanzerotti, L. J.: Statistical identification of solar wind origins of magnetic impulse events, J. Geophys. Res., 108, 1436, doi:10.1029/2003JA010202, 2003.

Kawano, H. and Russell, C. T.: Survey of flux transfer events observed with the isee 1 spacecraft: Dependence on the interplanetary magnetic field, J. Geophys. Res., 102, 11307-11313, 1997.

Kivelson, M. G. and Southwood, D. J.: Ionospheric Traveling Vortex Generation by Solar Wind Buffeting of the Magnetosphere, J. Geophys. Res., 96, 1661-1667, 1991.

Lucek, E. A., Horbury, T. S., Dunlop, M. W., Cargill, P. J., Schwartz, S. J., Balogh, A., Brown, P., Carr, C., Fornacon, K.-H., and Georgescu, E.: Cluster magnetic field observations at a quasi-parallel bow shock, Ann. Geophys., 20, 1699-1710, doi:10.5194/angeo-20-1699-2002, 2002.

Lucek, E. A., Horbury, T. S., Dandouras, I., and Rème, H.: Cluster observations of the Earth's quasi-parallel bow shock, J. Geophys. Res., 113, A07S02, doi:10.1029/2007JA012756, 2008.

McWilliams, K. A., Sofko, G. J., Yeoman, T. K., Milan, S. E., Sibeck, D. G., Nagai, T., Mukai, T., Coleman, I. J., Hori, T., and Rich, F. J.: Simultaneous observations of magnetopause flux transfer events and of their associated signatures at ionospheric altitudes, Ann. Geophys., 22, 2181-2199, doi:10.5194/angeo22-2181-2004, 2004.

Merka, J., Szabo, A., Safrankova, J., and Nemecek, Z.: Earth's bow shock and magnetopause in the case of a field-aligned upstream flow: Observation and model comparison, J. Geophys. Res., 108, 1269, doi:10.1029/2002JA009697, 2003.

Merka, J., Szabo, A., Slavin, J. A., and Peredo, M.: Threedimensional position and shape of the bow shock and their variation with upstream Mach numbers and interplanetary magnetic field orientation, J. Geophys. Res., 110, A04202, doi:10.1029/2004JA010944, 2005.

Nemecek, Z., Safrankova, J., Prech, L., Sibeck, D. G., Kokubun, S., and Mukai, T.: Transient flux enhancements in the magnetosheath, Geophys. Res. Lett., 25, 1273-1276, 1998.

Neugebauer, M., Goldstein, R., and Goldstein, B. E.: Features observed in the trailing regions of interplanetary clouds from coronal mass ejections, J. Geophys. Res., 102, 19743-19751, 1997.

Nishida, A.: The Geotail Mission, Geophys. Res. Lett., 21, 28712873, 1994.

Omidi, N., Blanco-Cano, X., and Russell, C. T.: Macrostucture of collisionless bow shocks: 1. Scale lengths, J. Geophys. Res., 110, A12212, doi:10.1029/2005JA011169, 2005.

Omidi, N., Sibeck, D. G., and Blanco-Cano, X.: Foreshock compressional boundary, J. Geophys. Res., 114, A08205, doi:10.1029/2008JA013950, 2009.

Onsager, T. G., Thomsen, M. F., Gosling, J. T., Bame, S. J., and Russell, C. T.: Survey of Coherent Ion Reflection at the QuasiParallel Bow Shock, J. Geophys. Res., 95, 2261-2271, 1990.

Plaschke, F., Glassmeier, K.-H., Sibeck, D. G., Auster, H. U., Constantinescu, O. D., Angelopoulos, V., and Magnes, W.: Magnetopause surface oscillation frequencies at different solar wind conditions, Ann. Geophys., 27, 4521-4532, doi:10.5194/angeo27-4521-2009, 2009.

Provan, G., Yeoman, T. K., and Milan, S. E.: CUTLASS Finland radar observations of the ionospheric signatures of flux transfer events and the resulting plasma flows, Ann. Geophys., 16, 14111422, doi:10.1007/s00585-998-1411-0, 1998.

Rème, H., Aoustin, C., Bosqued, J. M., Dandouras, I., Lavraud, B., Sauvaud, J. A., Barthe, A., Bouyssou, J., Camus, Th., CoeurJoly, O., Cros, A., Cuvilo, J., Ducay, F., Garbarowitz, Y., Medale, J. L., Penou, E., Perrier, H., Romefort, D., Rouzaud, J., Vallat, C., Alcaydé, D., Jacquey, C., Mazelle, C., d’Uston, C., Möbius, E., Kistler, L. M., Crocker, K., Granoff, M., Mouikis, C., Popecki, M., Vosbury, M., Klecker, B., Hovestadt, D., Kucharek, H., Kuenneth, E., Paschmann, G., Scholer, M., Sckopke, N., Seidenschwang, E., Carlson, C. W., Curtis, D. W., Ingraham, C., Lin, R. P., McFadden, J. P., Parks, G. K., Phan, T., Formisano, V., Amata, E., Bavassano-Cattaneo, M. B., Baldetti, P., Bruno, R., Chionchio, G., Di Lellis, A., Marcucci, M. F., Pallocchia, G., Korth, A., Daly, P. W., Graeve, B., Rosenbauer, H., Vasyliunas, V., McCarthy, M., Wilber, M., Eliasson, L., Lundin, R., Olsen, S., Shelley, E. G., Fuselier, S., Ghielmetti, A. G., Lennartsson, W., Escoubet, C. P., Balsiger, H., Friedel, R., Cao, J.-B., Kovrazhkin, R. A., Papamastorakis, I., Pellat, R., Scudder, J., and Sonnerup, B.: First multispacecraft ion measurements in and near the Earths magnetosphere with the identical Cluster ion spectrometry (CIS) experiment, Ann. Geophys., 19, 1303-1354, doi:10.5194/angeo19-1303-2001, 2001.

Retinò, A., Sundkvist, D., Vaivads, A., Mozer, F., André, M., and Owen, C. J.: In situ evidence of magnetic reconnection in turbulent plasma, Nat. Phys., 3, 236-238, 2007.

Ruohoniemi, J. M. and Baker, K. B.: Large-scale imaging of highlatitude convection with Super Dual Auroral Radar Network HFradar observations, J. Geophys. Res., 103, 20797-20811, 1998.

Russell, C. T., Petrinec, S. M., Zhang, T. L., Song, P., and Kawano, H.: The effect of foreshock on the motion of the dayside magnetopause, Geophys. Res. Lett., 24, 1439-1441, 1997.

Sanny, J., Tapia, J. A., Sibeck, D. G., and Moldwin, M. B.: Quiet-time variability of the geosynchronous magnetic field and its response to the solar wind, J. Geophys. Res., 107, 1443, doi:10.1029/2002JA009448, 2002.

Savin, S., Amata, E., Zelenyi, L., Budaev, V., Treumann, R., Lucek, E., Safrankova, J., Nemezek, Z., Khotyaintsev, Y., Andre, M., Buechner, J., Alleyne, H., Song, P., Blecki, J., Rauch, J. L., Romanov, S., Klimov, S., and Skalsky, A.: High kinetic energy jets in the Earth's magnetosheath: Implications for plasma dynamics and anomalous transport, Jetp. Lett.+, 87, 593-599, doi:10.1134/S0021364008110015, 2008. 
Schwartz, S. J.: Magnetic field structures and related phenomena at quasi-parallel shocks, Adv. Space Res., 11, 231-240, 1991.

Schwartz, S. J.: Shock and Discontinuity Mormals, Mach Numbers, and Related Parameters, in: Analysis Methods for MultiSpacecraft Data, edited by: Paschmann, G. and Daly, P. W., vol. 001, ISSI Sci. Reports, ESA, Noordwijk, The Netherlands, 249$270,1998$.

Schwartz, S. J. and Burgess, D.: Quasi-parallel shocks: A patchwork of three-dimensional structures, Geophys. Res. Lett., 18, 373-376, 1991.

Shevyrev, N. N. and Zastenker, G. N.: Some features of the plasma flow in the magnetosheath behind quasiparallel and quasiperpendicular bow shocks, Planet. Space Sci., 53, 95-102, 2005.

Shevyrev, N. N., Zastenker, G. N., and Du, J.: Statistics of low-frequency variations in solar wind, foreshock and magnetosheath: INTERBALL-1 and CLUSTER data, Planet. Space Sci., 55, 2330-2335, 2007.

Shue, J.-H., Song, P., Russell, C. T., Steinberg, J. T., Chao, J. K., Zastenker, G., Vaisberg, O. L., Kokubun, S., Singer, H. J., Detman, T. R., and Kawano, H.: Magnetopause location under extreme solar wind conditions, J. Geophys. Res., 103, 17691-17700, 1998.

Shue, J.-H., Chao, J.-K., Song, P., McFadden, J. P., Suvorova, A., Angelopoulos, V., Glassmeier, K. H., and Plaschke, F.: Anomalous magnetosheath flows and distorted subsolar magnetopause for radial interplanetary magnetic fields, Geophys. Res. Lett., 36, L18112, doi:10.1029/2009GL039842, 2009.
Sibeck, D. G. and Korotova, G. I.: Occurrence patterns for transient magnetic field signatures at high latitudes, J. Geophys. Res., 101, 13413-13428, 1996.

Sibeck, D. G., Baumjohann, W., Elphic, R. C., Fairfield, D. H., Fennell, J. F., Gail, W. B., Lanzerotti, L. J., Lopez, R. E., Luehr, H., Lui, A. T. Y., Maclennan, C. G., McEntire, R. W., Potemra, T. A., Rosenberg, T. J., and Takahashi, K.: The Magnetospheric Response to 8-Minute Period Strong-Amplitude Upstream Pressure Variations, J. Geophys. Res., 94, 2505-2519, 1989.

Sibeck, D. G., Omidi, N., Dandouras, I., and Lucek, E.: On the edge of the foreshock: model-data comparisons, Ann. Geophys., 26, 1539-1544, doi:10.5194/angeo-26-1539-2008, 2008.

Stone, E. C., Frandsen, A. M., Mewaldt, R. A., Christian, E. R., Margolies, D., Ormes, J. F., and Snow, F.: The Advanced Composition Explorer, Space Sci. Rev., 86, 1-22, 1998.

Stone, R. G. and Tsurutani, B. T., eds.: Collisionless Shocks in the Heliosphere: A Tutorial Review, vol. 34, Geophys. Monogr. Ser., AGU, Washington, DC, 1985.

Suvorova, A. V., Shue, J.-H., Dmitriev, A. V., Sibeck, D. G., McFadden, J. P., Hasegawa, H., Ackerson, K., Jelínek, K., Šafránková, J., and Němeček, Z.: Magnetopause expansions for quasi-radial interplanetary magnetic field: THEMIS and Geotail observations, J. Geophys. Res., 115, A10216, doi:10.1029/2010JA015404, 2010. 